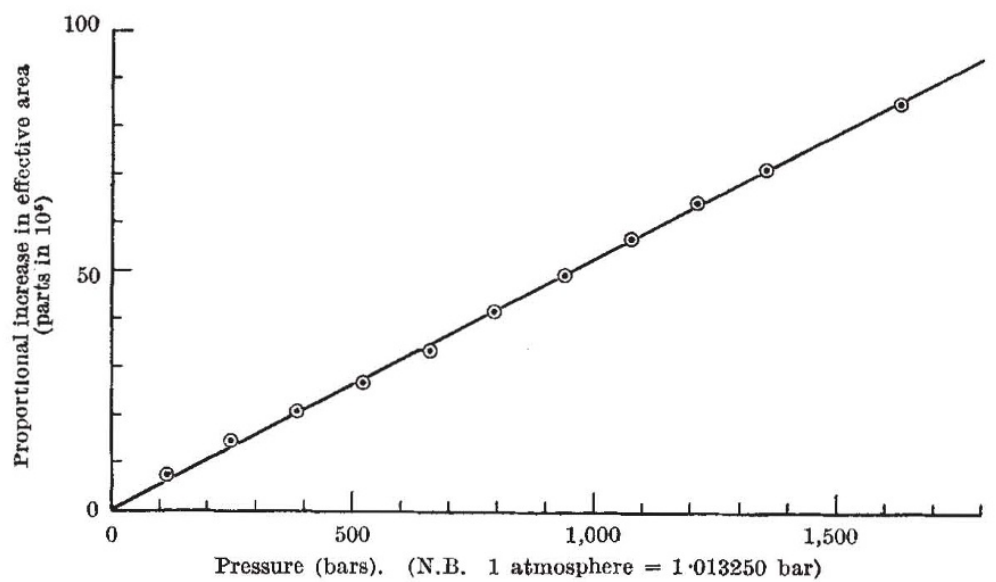
Fig. 1. Dependence of effective area on pressure for steel piston-cylinder assembly of
nominal area $0.02 \mathrm{sq}$. in.

balance may depend to some extent, at high pressures, on the viscous properties of the fluid used.

The present series of experiments at the National Physical Laboratory is intended to cover the range up to 3,000 atmospheres. The two materials so far used are a hard tool steel and a special type of bronze of high tensile strength. The strains of the materials loaded in tension, compression and shear have been measured over the range of stresses imposed in the pressure experiments. Within the limits of accuracy of these measurements, the stress-strain relationships were linear and conformed to a fixed ratio of the elastic moduli of $1 \cdot 44: 1$. Measurements in three directions at right angles which were made by the ultrasonic-wave velocity method, using longitudinal and shear waves, indicated the materials to be satisfactorily isotropic. The accuracy of construction of the assemblies is largely limited by the accuracy with which the cylinder bore can be made and measured. Owing to recent improvements which have been made in the Metrology Division of the Laboratory in the measurement of the form and diameters of cylinder bores ${ }^{3}$, it has proved possible to construct piston-cylinder assemblies to the requisite precision, and with the required degree of similarity.

The results of the present series of measurements show that the method is capable of a very satisfactory degree of accuracy and consistency, and permits the measurement of the variation in effective area over a wide range of pressure to within a few parts in $10^{5}$ of the total area. In fact, over small ranges of pressure, variations in effective area of only a few parts in $10^{6}$ of the total area can be determined. An example of the results obtained is shown in Fig. 1, where it will be seen that a particular steel pistoncylinder assembly of nominal area 0.02 sq. in. may change in effective area by an amount of the order 1 part in 2,000 per 1,000 bars of applied pressure. In this instance the change proved to be a linear function of pressure to the order \pm 1 part in $10^{5}$ of the total area.

While the present series of tests is intended to cover the range up to 3,000 atmospheres, plans are being made to extend this range to higher pressures so far as may be practicable, and some further interesting possibilities of the similarity method are under investigation. Full details of this work will be published in a further paper. From the nature of the method it seems that it should be applicable over virtually any range over which pressure balances can be used, and in which two materials having the necessary properties are available. The main difficulty in the method resides in the construction of the highly accurate pistons and cylinders which are required. Once these are available, the experimental work in determining the variation of effective area is simple, quick and convenient.

We have so far dealt only with the variation in effective area with pressure, but at some point of the scale the effective area must be measured in absolute terms. This link is most easily made at a low pressure where distortion is known to be negligible. The present procedure at the National Physical Laboratory is to use two independent methods to obtain this measurement: $(a)$ direct measurement by balancing at a low pressure against a mercury manometer; (b) by computing the effective area from the measured dimensions of the piston and cylinder.

These two methods of measurement have given agreement to within 2 parts in $10^{5}$; but it is thought that this accuracy can be somewhat improved.

I acknowledge the helpful co-operation of the Metrology Division of the Laboratory, which undertook the measurement and construction of the special piston-cylinder assemblies required, and of the Engineering Section of the Physics Division, which determined the elastic constants of the materials.

The work described was carried out as part of the research programme of the National Physical Laboratory, and this communication is published by permission of the Director of the Laboratory.

[May 19

${ }^{1}$ Holborn, L., and Schultze, H., Ann. d. Phys., 47, 1092 (1915).

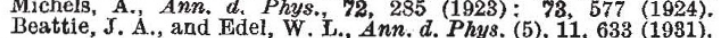

- Bett, K. E., Hayes, P. F., and Newitt, D. M., Phil. Trans. Roy. Soc., A, 247, 59 (1954.)., (This paper gives extensive references.)
Sold a Taylerson, C. O., Report of Symposium on Engineering Dimensional
Metrology, N.P.L., Oct. 1953, 1, 73 (H.M.S.O., 1955).

\section{THE COMMONWEALTH MYCOLOGICAL INSTITUTE}

\section{BY DR. S. P. WILTSHIRE Director}

$\mathrm{T}$ HE opening of the new building of the Commonwealth Mycological Institute at Kew by H.R.H. the Duke of Edinburgh on July 13 was a notable ovent in the history of the Institute. Founded in 1921, the Institute first occupied two houses, 17-19 Kew Green, but in 1930 moved to a building in Ferry Lane, erected with the help of the Empire Marketing Board. That building rapidly proved inadequate and plans were prepared for an extension of it to be put before the Commonwealth Mycological Conference arranged for September 1939, but which had to be abandoned owing to the outbreak of war. Since 1939 the work of the Institute has increased enormously, and the Fourth Commonwealth Mycological Conference, held. in 1948, recommended the immediate erection of a new building. The freehold 
site on which the new building stands became available and was purchased in 1950 through the prompt action of the chairman of the Executive Council. Detailed plans were put before the Commonwealth Agricultural Bureaux Review Conference in 1950 and approved; but the cost was to be borne on a separate vote. Administrative difficulties arose and the funds for the building were not sanetioned until 1953. Building operations started in May 1954, and were just completed in time for the opening. The lack of accommodation has been most seriously felt ; but the new building now erected to the plans of Messrs. Waterhouse and Ripley affords adequate and most suitable quarters.

The need for additional space may be judged from the fact that the staff of the Institute now numbers thirty-seven and includes ten mycologists covering the editorial and identification services, including the culture collection, six abstractors, five of whom are linguists covering most of the languages in the literature of the subject, a herbarium recording staff of three, an indexer-librarian and five technical assistants, besides clerical staff. In addition, there is a pool of three plant pathologists attached to the Institute by arrangement with the Colonial Office, which provides the necessary finance. These plant pathologists undertake research into the cause and control of disease in the Colonial dependencies when requircd and may be moved to danger spots at short notice.

In his address, the Duke of Edinburgh stressed the importance of plant disease control in increasing and maintaining agricultural production. The spear-head of the attack on plant disease is, he emphasized, research, and the fight is seldom once and for all. New diseases or new variations of old diseases are always eropping up. Plant diseases could have disastrous effects not only on the economy but also on the social pattern of a country. The Institute has the important task of making it easier for research workers to follow what is going on elsewhere and to avoid duplication of effort. Much is heard, he said, of the invisible links of the Commonwealth, but this is one of the tangible ones. He was glad to find it possible for Cornmonwealth countries to co-operate in this particular field, and he hoped everyone who works at the Institute would find it a rewarding occupation.

The building is in the Georgian style to fit in with the surrounding architecture. The ground floor is devoted wholly to the library, apart from a small room for the Director. The literature of plant pathology and mycology increased enormously during the Second World War, and as one of the main functions of the Institute is to abstract this information for its journal, the Review of Applied Mycology, adequate library accommodation is absolutely vital for its work. The opening ceromony took place in this spacious room, which in due course is to be fitted with the requisite shelving and furniture. The room is well lit by fiftecn windows, and tables are to be provided for fifteen readers. For several years the purchase of journals has had to be limited from lack of space, and the need for reprints of plantpathological and mycological articles published in past as well as recent years, especially from foreign countries, is very great. The library of the Institute should be one of the best phytopathological and mycological libraries in the world, and the cooperation of all plant pathologists is earnestly sought in supplying or making available the necessary literature. The collection of 'separates', now number- ing some sixty thousand pamphlets, is to be incorporated in the library.

Besides the Review of Applied Mycology, the Institute publishes distribution maps of plant diseases, the "Index of Fungi", listing all new species of fungi described throughout the world, the Review of Medical and Veterinary Mycology, surveying the world's literature on this subject, Mycological Papers, recording the results of research in systematic mycology, and the quarterly Commonwealth Phyto. pathological News. The Institute has also issued several books, the best known being the "Dictionary of Fungi", by G. C. Ainsworth and G. R. Bisby.

The first floor of the new building accommodates the herbarium of the Institute, which now contains about 65,000 collections. The identification service, maintained for the benefit of Commonwealth plant; pathologists and mycologists, is the other major activity of the Institute. From the start, the Institute has recognized that investigations into the etiology of plant diseases can only be made by plant pathologists working in the countries where the diseases occur; and on the other hand, the identification of the pathogens can only be carried out by trained systematists working in a herbarium with adequate literature and specimens available. The identification of fungi is difficult work and requires special qualities and prolonged training. Mr. E. W. Mason, chief mycologist, has developed a herbarium technique which is both unique and valuable and has built up an enthusiastic staff for this arduous task. For years the staff employed in the work have been greatly hampered by overcrowded conditions. In the new building, the main herbarium runs the whole length of the building, with the exception of a room for the chief mycologist. Rooms are also provided on the south side for herbarium records, a drying room where specimens can be dried for the herbarium, a culture room, and a disinfestation room where all incoming material is disinfested from beetles and other insects with methyl bromide. Fluorescent lighting enables the herbarium cases to be placed in rows, with a resultant great saving of space.

The top floor comprises four rooms for visitors, with eight working benches, and two large rooms for the culture collection, one a preparation room, and the main laboratory occupying the whole of the far end of the building. The collection now comprises upwards of two thousand cultures and is constantly being added to. Adequate storage cabinets designed for the work, incubators, cupboards, desks and benches make the laboratory a well-equipped and pleasant room for culture work. Special cabinets for making transfers have not been found necessary and are not incorporated in the new laboratory, with a corresponding saving in cost.

The basement runs the whole length of the building and provides accornmodation for photographic darkrooms, comprising two developing rooms, one studio and one microfilm room, storage room for publications, the boiler with space provided for a second boiler should the building ever be extended, a workshop, and a room for electric and gas meters. The building is constructed of reinforced concrete with hot-water pipes embedded in the floors, thermostatic control and automatic firing of the boiler, and provision for the mechanical delivery of the fuel from suitably constructed lorries. The plans provide for an extension of the building to double its present 
size should this be required, and the internal walls can readily be removed without damage to the structure if a rearrangement of the rooms should prove desirable in the years to come.

The old building is being retained to house the administration and editorial and abstracting staffs, and one room is set apart for the pool of plant pathologists when they happen to be working in Great Britain.

\section{OBITUARY}

\section{Dr. Bernard J. Flurscheim}

Dr. Bernard J. Flurscheim, who died recently at his home in Fleet, was in his eighty-first year. So passes the last of the great pre-electronic builders of the theory of organic ehemistry.

After a school education on classical lines at Baden and Bournemouth, Flurscheim made his first scientific studies in the University of Geneva; afterwards he worked with Werner in Zurich, and with Thiele in Strassburg. He took his Ph.D. degree in Heidelberg in 1901. In 1905 he set up his house in Fleet, in the garden of which he built the laboratory, where he worked, until other duties claimed him in the First World War. For the periods 1905-7 and 1925-28 he worked in the Royal Institution in London.

In his main scientific work, the provision of organic chemistry with a theoretical framework, Flurscheim was natural successor to both Werner and Thiele: he started from Werner's ideas of the divisibility of chemical affinity when discussing its distribution on molecules, and it ranks as a major and lasting discovery that his scisisus of distribution involve a generalization of Thiele's theory of coit. jugation, as is to-day so readily appreciated in clectronic terms.

Flurscheim's first paper of classical importance, published in the Journal für praktische Chemie in
1902, described the first rational explanation of orientation in aromatic substitution. In 1909-10 he published in the Journal of the Chemical Society two papers of like importance on the strengths of acids and bases. Here he was extending the application of his theory from the kinetic to the thermodynamic field, thereby showing that his valency redistributions apply not only to activated states but also to normal molecules. To-day, with the aid of the quantum theory, we re-express this, too, in electronic terms, and call the result mesomerism or resonance.

Flurscheim published many other papers of more limited importance. He never participated in the remoulding of his theories in conformity with the electronic theory of valency and quantum mechanies. However, the largely correct form of Flurscheim's theories made this task of recasting them a particularly easy one for others.

His discovery of tetranitroaniline, perhaps the most powerful of known explosives at the time of its discovery, was an accidental result of his work in the Fleet laboratory, directed as this was to the experimental control of his theoretical ideas. It was an accident that he sometimes regretted, inasmuch as it led him into commercial work, to which he was not well suited. However, it enabled him to render notable service during the First World War, when, on the request of the late Lord Moulton, he undertook supervision of the large-scale manufacture of this explosive in the United States. During the Second World War he worked as gas identification officer for the A.R.P. authorities.

Flurscheim did not make human contacts easily or treat them lightly. $\mathrm{H}_{\theta}$ was devoted to his family, and to a few firm friends. His chief personal hobbies

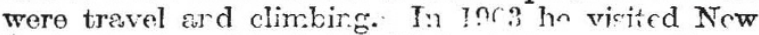

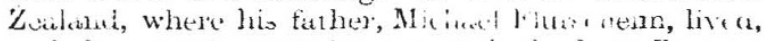

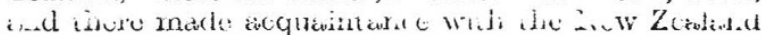
Alps. He know las Aips oi ismupe very well. Lo leaves a widow, a daughter and a son.

C. K. Ingold

\section{NEWS and VIEWS}

\section{Chemistry at University College, London :} Prof. D. P. Craig

A NEW chair of ehemistry at University College, London, has been instituted, and Prof. D. P. Craig, of the University of Sydney, is to be its first occupant. $H_{\theta}$ will take up the duties of the chair in 1956. Prof. Craig took his first degree with first-class honours in chemistry in 1940 in the University of Sydney, where he remained as Commonwealth Research Fellow until 1942. During 1942-44 he served with the rank of captain in the Australian military forces. In 1946 he was appointed lecturer in chemistry in the University of Sydney, and during 1946-50 he was Turner and Newall Fellow in the University of London, being appointed lecturer in chemistry at University College, London, in 1950; since 1952 he has been professor of physical chemistry in the University of Sydney. Prof. Craig's research career is that of an experimental physical chemist with deep knowledge of, and interest in, the theory of chemistry. He has published work on co-ordination compounds with particular reference to the nature of metal-ligand bonds, on aromatic character and the conditions for its appearance, on the excited states of un- saturated and aromatic molecules, on the excited states of crystals, and on the relation between molecular and crystal states. He has also contributed to the methodology of quantum mechanies by introducing configuration interaction into molecular orbital theory, and clarifying the role of polar structures in valency-bond theory. The addition of so accomplished a theoretician to the Chemistry Department of University College, where co-ordination chemistry, molecular spectroscopy and crystal chemistry are all intensively studied, seems perticularly appropriate.

\section{Sir William Hamilton (1805-65)}

ONE of the most brilliant mathematicians of modern times, William Rowan Hamilton was born in Dublin one hundred and fifty years ago, at midnight between August 3 and 4, 1805, of a Scottish family that had settled in Ireland. He was a precocious child, being able to read Hebrew at the age of seven; at twelve he had mastered Latin, Greek and the leading Continental languages, and had acquired some knowledge of Syriac, Persian, Arabic, Sanskrit, Hindustani and Malay. Quite early he showed his genius for mathematics, and in his 